\title{
RAINFALL-RUNOFF MODELLING OF THE WEST RAPTI BASIN, NEPAL
}

\author{
Bibek Thapa ${ }^{1 *}$, Anusha Danegulu ${ }^{1}$, Naresh Suwal ${ }^{2}$, Surabhi Upadhyay ${ }^{3}$, Bikesh Manandhar $^{1}$, \\ and Rajaram Prajapati ${ }^{3}$ \\ ${ }^{1}$ Institute of Engineering (IOE), Pulchowk Campus, Pulchowk, Lalitpur \\ ${ }^{2}$ Khwopa College of Engineering, Liwali, Bhaktapur \\ ${ }^{3}$ Smartphones For Water Nepal (S4W-Nepal), Thasikhel, Lalitpur \\ *E-mail: bibekthapa@gmail.com
}

\begin{abstract}
A hydrological model helps in understanding, predicting, and managing water resources. The HEC-HMS (Centre for Hydrological Engineering - Hydrological Modelling Systems, US Army Corps of Engineers) is one of the hydrological models used to simulate rainfall-runoff and routing processes in diverse geographical areas. In this study, a semi-distributed hydrological model was developed using HEC-HMS for the West-Rapti river basin. The model was calibrated and validated at each outlet of sub-basins and used to simulate the outflow of each sub-basins of the West Rapti river basin. A total of eight rain gauge stations, five meteorological stations, and three hydrological stations, within the basin, were used. The simulated results closely matched the observed flows at the three gauging stations. The Nash-Sutcliffe Efficiency indicated the good model performance of the simulated streamflow with the observed flow at two stations and satisfactory model fit at one station. The performance based on percentage bias and root mean square error was good. This model provides a reference to study water balance, water resource management, and flooding control of the West Rapti basin and can be replicated in other basins.
\end{abstract}

\section{Keywords}

Rainfall-runoff, HEC-HMS, West Rapti Basin, Hydrology

\section{Introduction}

Withouthydrologicalstudiesand understanding of basin water dynamics, we cannot imagine water resource planning and management. Due to climate change and anthropogenic activities, the hydro-geomorphology of the river is severely altered, which makes it more complex to study the stochastic nature of the river. The availability of data is vital in hydrological studies. With less or without data, the quantitative study and forecasting of the hydrologic process of runoff generation and its aftermath resulted in the watershed to the outlet become the most difficult work of hydrology(Halwatura \& Najim, 2013). For sustainable water resource management, water managers need to simulate and forecast rainfall and its corresponding runoff in the river. There are a number of hydrological models to predict the streamflow from the watersheds, either using 
Nepal Engineers' Association, Gandaki observed data or using empirical and statistical Methods. Of them, a rainfall-runoff model is frequently used(Kafle, 2019). Hydrological models in water science can be categorized as empirical or conceptual, 1D or 2D or 3D, lumped or semi-distributed or distributed, steady or unsteady, and deterministic or stochastic. The hydrological model is used to find out the watershed hydrological response due to rainfall and the priority of the models depends on the nature of watersheds, the purpose of the study, and the objective of the hydrological forecast. The HEC-HMS (Centre for Hydrological Engineering - Hydrological Modelling Systems, US Army Corps of Engineers) is one of the hydrological models used to simulate precipitation-runoff and routing processes. Many studies show the ability of the HEC-HMS model to simulate and forecast streamflow and its suitability in diverse geographical areas (Gebre, 2015; Paudel, Basnet, \& Sherchan, 2019; Sampath, Herath, \& Weerakoon, 2015; Wang, Zhang, \& Baddoo, 2016). The strong aspects of a semi-distributed model like HEC-HMS are that "they are less demanding on input data than distributed models, and their structure is more physically based than the structure of lumped models"(Gebre, 2015). The details about the HEC-HMS can be found in the technical reference manual of Hydrologic modelling system HEC-HMS(Feldman, 2000).

Flooding is a common event in West Rapti River, and the river inundated several villages in the downstream each year during monsoon seas(Adhakari, 2013). To mitigate anticipated flooding and to warn about flooding to the nearby resident, an early warning system is a must. In flood forecasting modeling, rainfallrunoff simulation plays a vital role.
The study established a semi-distributed hydrological model using HEC-HMS for the West Rapti river basin. The model was calibrated at each outlet of sub-basins using data from 1991 A.D to 1995 A.D. The model is validated using the data from 1996 A.D to 2000, and the model is used to simulate the outflow of each sub-basins of the West Rapti river basin. The model will provide a reference to study water balance, water resource management, and flooding control of the basin.

This paper addresses the development of a rainfall-runoff hydrologic model for West Rapti basin. The prepared hydrologic model simulates the continuous response of the catchment under possible precipitation scenarios.

\section{Materials and Methods}

\section{Study Area}

The study area is the West Rapti river basin, located in the mid-western region of Nepal. The main river is named West Rapti, downstream of the confluence of the Jhimruk river and Mari river. The basin has an area of 5,139 sq.km. The basin covers six districts ,namely, Rukum West, Rukum East, Pyuthan, Dang, Argakhanchi, and Kapilvastu. The drainage network is demonstrated in Figure 1. The average slope of the basin is $24^{\circ}$. The major source of runoff in the basin is monsoon precipitation and groundwater (Talchabhadel \& Sharma, 2014).

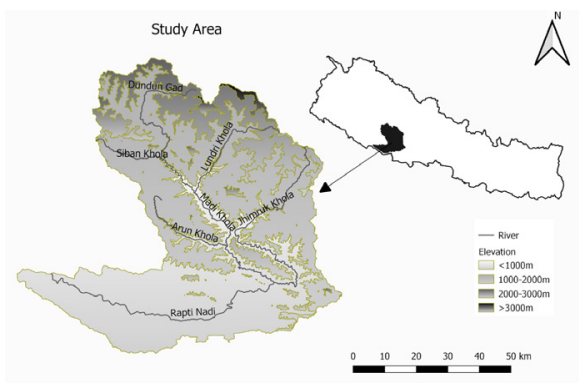

Figure 1: Location of West Rapti Basin 


\section{Data}

The study used the daily precipitation data, maximum and minimum temperature, humidity, wind speed, solar radiation, and daily discharge data acquired from the Department of Hydrology and Meteorology (DHM) (http:// dhm.gov.np/) Nepal, from 1991 to 1995 A.D. and 1996 to 2000 A.D. for calibration and validation, respectively. Rainfall data were collected from eight rain gauge stations and the flow data are taken from three hydro gauge stations within the basin. The details of the rain gauge stations, metrological stations, and hydrological stations are shown in Table 1, Table 2, and Table 3, respectively.

Table 1: Details of the rain gauge stations (Source: http://dhm.gov.np/)

\begin{tabular}{|l|l|l|l|l|l|l|l|l|l|}
\hline \multirow{2}{*}{ S.No. } & \multirow{2}{*}{ Index No. } & \multirow{2}{*}{ Station name } & \multirow{2}{*}{ District } & \multicolumn{2}{|l|}{ Latitude } & \multicolumn{2}{l|}{ Longitude } & \multirow{2}{*}{ Elevation (m) } \\
\cline { 5 - 10 } & & & deg & min & deg & min & \\
\hline 1 & 501 & Rukumkot & Rukum & 28 & 36 & 82 & 38 & 1560 \\
\hline 2 & 504 & Libang Gaun & Rolpa & 28 & 18 & 82 & 38 & 1270 \\
\hline 3 & 505 & Bijuwartar & Pyuthan & 28 & 6 & 82 & 52 & 823 \\
\hline 4 & 510 & Koilabas & Dang & 27 & 42 & 82 & 31 & 320 \\
\hline 5 & 512 & $\begin{array}{l}\text { L u w a n j u l a } \\
\text { Bazar }\end{array}$ & Salyan & 28 & 18 & 82 & 17 & 885 \\
\hline 6 & 514 & $\begin{array}{l}\text { M u s i k o t } \\
\text { (Rukumkot) }\end{array}$ & Rukum & 28 & 38 & 82 & 29 & 2100 \\
\hline 7 & 515 & Ghorai & Dang & 28 & 3 & 82 & 30 & 634 \\
\hline 8 & 723 & Bhagwanpur & Kapilvastu & 27 & 41 & 82 & 48 & 80 \\
\hline
\end{tabular}

Table 2: Details of meteorological stations (Source: http://dhm.gov.np/)

\begin{tabular}{|l|l|l|l|l|l|l|l|l|l|}
\hline S.N. & $\begin{array}{l}\text { In d e x } \\
\text { No. }\end{array}$ & Station name & District & \multicolumn{2}{|l|}{$\begin{array}{l}\text { Latitude } \\
\text { deg }\end{array}$} & \multicolumn{2}{|l|}{$\begin{array}{c}\text { Lonin } \\
\text { deg }\end{array}$} & Min & \multicolumn{2}{|l|}{$\begin{array}{l}\text { Elevation } \\
(\mathrm{m})\end{array}$} & Data \\
\hline 1 & 406 & $\begin{array}{l}\text { Surkhet } \\
\text { (Birendranagar) }\end{array}$ & Surkhet & 28 & 36 & 81 & 37 & 720 & Wind \\
\hline 2 & 420 & $\begin{array}{l}\text { Nepalgunj } \\
\text { Airport }\end{array}$ & Banke & 28 & 6 & 81 & 40 & 165 & wind \\
\hline 3 & 514 & $\begin{array}{l}\text { Musikot } \\
\text { (Rukumkot) }\end{array}$ & Rukum & 28 & 38 & 82 & 29 & 2100 & $\begin{array}{l}\text { Temperature, } \\
\text { Humidity }\end{array}$ \\
\hline 4 & 515 & Ghorai & Dang & 28 & 3 & 82 & 30 & 634 & $\begin{array}{l}\text { Temperature, } \\
\text { Humidity, sunshine }\end{array}$ \\
\hline 5 & 715 & Khanchikot & Argakhanchi & 27 & 56 & 83 & 9 & 1760 & $\begin{array}{l}\text { Temperature, } \\
\text { Humidity }\end{array}$ \\
\hline
\end{tabular}


Nepal Engineers' Association, Gandaki

Table 3: Details of the hydrological stations (Source: http://dhm.gov.np/)

\begin{tabular}{|l|l|l|l|l|l|l|l|l|l|l|l|}
\hline \multirow{2}{*}{ S.N. } & \multirow{2}{*}{$\begin{array}{l}\text { Index } \\
\text { No. }\end{array}$} & \multirow{2}{*}{ Location } & \multirow{2}{*}{ River } & \multicolumn{4}{|l|}{ Latitude } & \multicolumn{3}{|l|}{ Longitude } & \multirow{2}{*}{ Elevation (m) } \\
\cline { 5 - 11 } & & & deg & min & sec & deg & min & sec & \\
\hline 1 & 330 & Nayagaon & Mari Khola & 28 & 4 & 20 & 82 & 48 & 0 & 536 \\
\hline 2 & 350 & Bagasoti Gaon & Rapti & 27 & 54 & 0 & 82 & 51 & 0 & 218 \\
\hline 3 & 360 & Jalkundi & Rapti & 27 & 56 & 50 & 82 & 13 & 30 & 381 \\
\hline
\end{tabular}

\section{HEC-HMS Model Setup}

For HEC-HMS projects, components like a basin, meteorological components, control specification, and input data are required. The basin model is generated from the ArcHydro tool from ESRI about the delineated sub-basins (Figure 2). The meteorological component contains observed flow data, potential evapotranspiration data, and precipitation data. The precipitation data is spatially and temporally distributed using gauge weights calculated by the Theissen polygon method in ArcGIS. The simulation period and time step are fixed in the control specification component, and input data represents all observed data like precipitation and discharge required for calibration and validation purposes.

To model the infiltration losses, a deficit and constant loss method were adopted in combination with simple canopy and simple surface Methods to incorporate the loss of moisture through interception by vegetation and filling of depression storage in the basin, respectively. The parameters required were obtained from the soil map and land use map. Linear Reservoir and Snyder Unit Hydrograph Methods were employed to model the baseflow and transformation of excess rainfall into streamflow hydrograph, respectively.

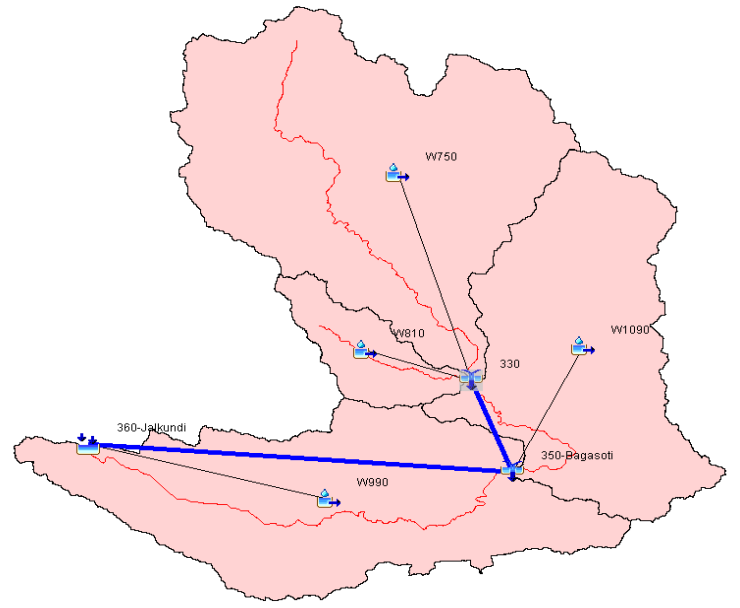

Figure 2: West Rapti Basin Model

\section{Calibration and validation}

Once all the parameters were input in the HECHMS project of the basin, output was obtained as the simulated discharge values, which were then compared with the observed data of the same period to determine the reliability of the result. Calibration was done manually and also through optimization techniques to match the observed values and simulated values. Then, validation was carried out using the optimized parameters in different periods for the same basin to validate the result from calibration.

The manual calibration of loss, transform, and baseflow parameters were conducted using observed streamflow data from the three gauging stations within the West Rapti Basin viz. 330,350 and 360, from 1991 through 1995. The hydrologic cycle was modelled by using the HEC-HMS Methods of canopy storage, 
surface storage, deficit and constant loss and linear reservoir baseflow. The calibration was initialized using plausible ranges obtained from the HEC-HMS Help manual. These values were manually modified until a good fit between the simulated and observed streamflow was obtained. The goodness of fit was evaluated using hydrograph visualization and computed statistical performance measures.

\section{Model Performance Evaluation}

The time series output of simulated and observed flows form the results after the simulation run in the HEC-HMS model were analyzed in a spreadsheet to compute the statistical measures for performance evaluation.

Factors like Nash-Sutcliffe model efficiency (NSE), Root mean square error (RMSE), Percentage error in volume (PEV), and Coefficient of Correlation $\left(\mathrm{R}^{2}\right)$ were the basis to evaluate the performance of the hydrological model which is shown in Table 4. The methodological framework of the study is shown in Figure 3.

Table 4: General performance ratings for recommended statistics (Moriasi et al., 2007)

\begin{tabular}{llll}
\hline Performance Rating & NSE & PBAIS & RSR \\
\hline Very Good & $0.75<$ NSE $\leq 1.00$ & PBAIS $\leq \pm 10$ & $0.00<$ RSR $\leq 0.50$ \\
Good & $0.65<$ NSE $\leq 0.75$ & $\pm 10<$ PBAIS $\leq \pm 15$ & $0.50<$ RSR $\leq 0.60$ \\
Satisfactory & $0.50<$ NSE $\leq 0.65$ & $\pm 15<$ PBAIS $\leq \pm 25$ & $0.60<$ RSR $\leq 0.70$ \\
Unsatisfactory & NSE $\leq 0.50$ & PBAIS $\geq \pm 25$ & RSR $\geq 0.7$ \\
\hline
\end{tabular}

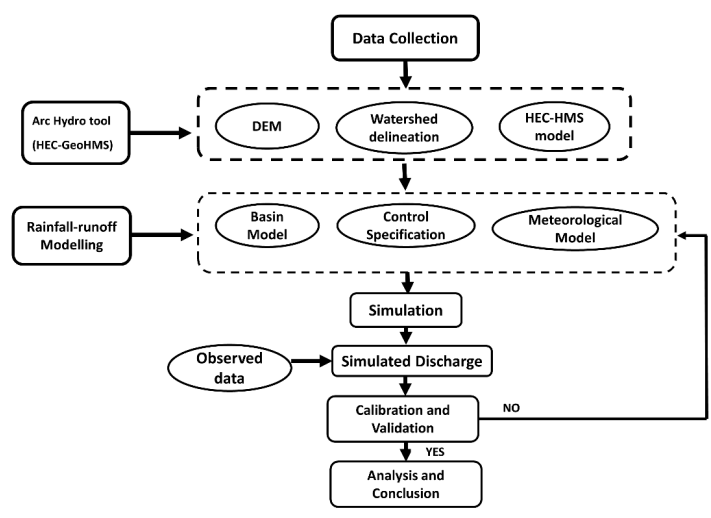

Figure 3: Flowchart of Methodology

\section{Results}

\section{Calibration and Validation}

The observed and simulated hydrographs form the developed rainfall-runoff model are shown in Figures 4, 5 \&6. The comparison shows a close agreement between the simulated and observed streamflow in terms of the timing of the peaks and general streamflow distribution over the calibration period.

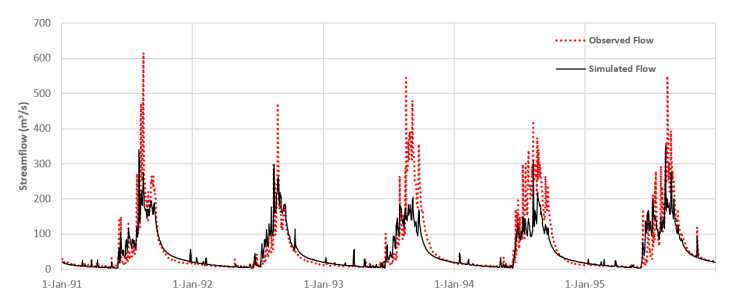

Figure 4: Daily Hydrograph at Gauging Station 330 (1991-1995)

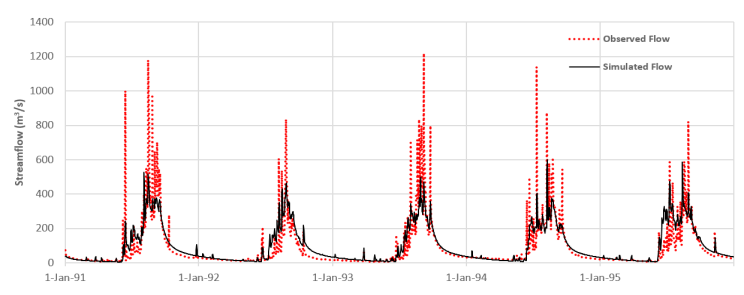

Figure 5: Daily Hydrograph at Gauging Station 350 (1991-1995) 


\section{Nepal Engineers' Association, Gandaki}

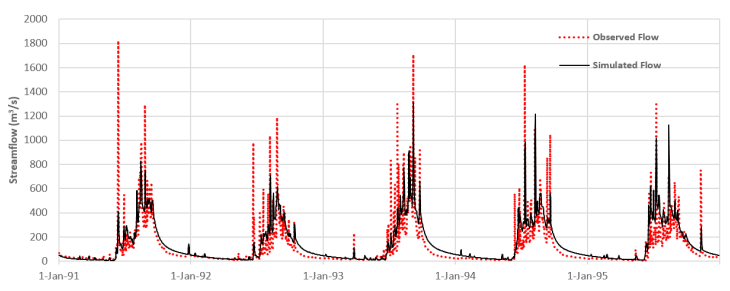

Figure 6: Daily Hydrograph at Gauging Station 360 (1991-1995)

Table 5 shows the optimized values of the calibration parameters of different subbasins for the study area. The validation of the optimized parameters was performed by running the prepared model using same parameters used in the calibration period for the period of validation period of 19962000 to assess the performance of the model to predict runoff at the three aforementioned gauging stations. The simulated and observed streamflow comparison graphs are shown in Figures 7, 8 \& 9 for the validation period of 1996-1999. The comparison shows a close agreement between the simulated and observed streamflow in terms of the timing of the peaks and general streamflow distribution over the validation period.

Table 5: Calibrated Parameters

\begin{tabular}{lllll}
\hline \multirow{2}{*}{ Parameters } & \multicolumn{2}{l}{ Sub-basins } & & \\
& W750 & W810 & W1090 & W990 \\
\hline Max canopy storage(mm) & 2.5 & 2.5 & 2.5 & 2.5 \\
Max surface storage (mm) & 10 & 10 & 10 & 10 \\
Initial deficit (mm) & 10 & 10 & 5 & 10 \\
Max deficit (mm) & 55 & 55 & 60 & 45 \\
Constant rate (mm/hr) & 1.25 & 1.25 & 1.5 & 1 \\
Impervious (\%) & 10 & 10 & 10 & 10 \\
Snyder UH standard lag (hr) & 8 & 3 & 12 & 8 \\
Snyder UH peaking coefficient & 0.75 & 0.65 & 0.65 & 0.6 \\
GW1 coefficient $(\mathrm{hr})$ & 300 & 450 & 300 & 300 \\
GW2 coefficient $(\mathrm{hr})$ & 2500 & 1000 & 2500 & 2000 \\
\hline
\end{tabular}

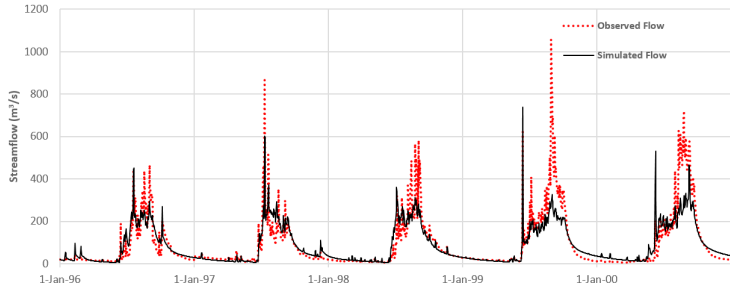

Figure 7: Daily Hydrograph at Gauging Station 330 (1996-2000)

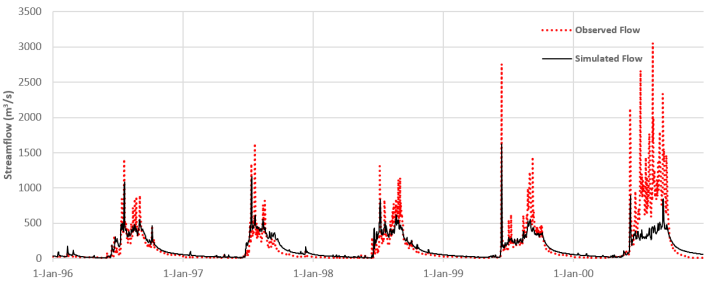

Figure 8: Daily Hydrograph at Gauging Station 350 (1996-2000) 


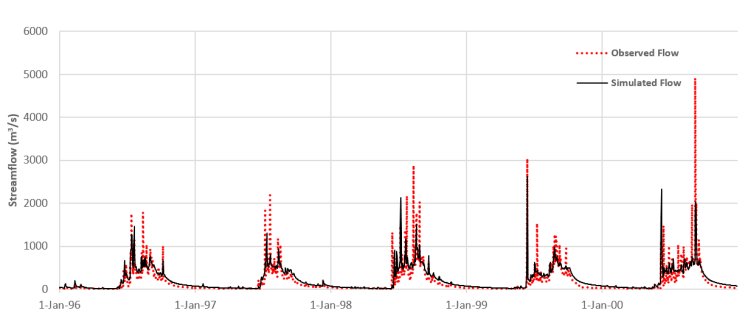

Figure 9: Daily Hydrograph at Gauging Station 360 (1996-2000)

\section{Model performance evaluation}

The values of NSE, PBAIS, and RSR at different gauging stations for both calibration and validation periods are listed in Table 6 and Table 7 . The desirable performance ratings of these statistical measures are presented in Table 4 in the earlier section.

Table 6: Performance Measures for Calibration Period

\begin{tabular}{llll}
\hline Performance & \multicolumn{3}{l}{ Gauging Stations } \\
Measures & $\mathbf{3 3 0}$ & $\mathbf{3 5 0}$ & $\mathbf{3 6 0}$ \\
NSE & 0.715 & 0.712 & 0.658 \\
Percent Bias & -14.36 & 9.28 & 24.43 \\
RSR & 0.5 & 0.5 & 0.6 \\
\hline
\end{tabular}

Table 7: Performance Measures for Validation Period

\begin{tabular}{llll}
\hline Performance & \multicolumn{3}{l}{ Gauging Stations } \\
Measures & $\mathbf{3 3 0}$ & $\mathbf{3 5 0}$ & $\mathbf{3 6 0}$ \\
NSE & 0.71 & 0.764 & 0.652 \\
Percent Bias & -5.09 & 11.03 & 24.78 \\
RSR & 0.5 & 0.5 & 0.6 \\
\hline
\end{tabular}

The performance of the model ranges from satisfactory to very good based on different statistical measures. Based on Nash-Sutcliffe Efficiency (NSE), the model performance is good at gauging stations 330 and 350 for both calibration and validation periods. Whereas, the models perform satisfactorily to model flow at gauging station 360 based on NSE. Based on percent bias (PBAIS), the model's performance Volume 2 Issue 1 ranges from good to very good except for the gauging station 360 , where its performance is satisfactory. Based on Root Mean Square Error (RSR), the model performance mostly ranges from good to very good for both calibration and validation period.

\section{Discussion}

The simulated results closely matched the observed flows at the two gauging stations on the upper reach. The model performance on the lowermost gauging station was satisfactory (Station 360, NSE 0.658) compared to very good performance on the remaining stations (Station 330 and 350, NSE $0.715 \& 0.712$ respectively) for the calibration period. The model performance was similar for the validation period with NSE of 0.652 for gauging station 360 and NSE of 0.71 and 0.764 at gauging stations 330 and 350, respectively. The performance-based on RSR and PBIAS is also somewhat similar. The two gauging stations of the upper reach lie in the Hilly region, and the remaining one falls entirely on the flat Terai. The model is seen to capture hydrology of hilly region more successfully.

The parameters used for the deficit and constant model are related to soil properties and require field investigations at a high spatial resolution for a more accurate assessment of the parameter. Primary data could not be collected and secondary data were not available. This limitation affects the accuracy of the model to simulate the daily streamflow to some extent.

Continuous hydrologic models requires evapotranspiration to be included in it. The daily evapotranspiration input calculated from Penman's equation separately outside of the HEC-HMS environment performed well when coupled with canopy storage, surface storage and deficit and constant model. 
Nepal Engineers' Association, Gandaki

The deficit and constant loss model was successful to capture direct runoff which contributes to majority of stream flow in wet seasons. The groundwater stored contributes to majority of streamflow in dry season. This dry season was successfully captured by the linear reservoirs.

\section{Conclusion}

The hydrologic model, developed in HECHMS, was able to simulate continuous rainfallrunoff scenario of the West Rapti basin. Interception and depression storage were modelled using canopy and surface Methods. The infiltration process was modelled using a deficit and constant loss method whereas the linear reservoir method in HEC-HMS was used to model the baseflow. The Nash-Sutcliffe Efficiency indicated good model fit of the simulated streamflow with the observed flow at stations 330 and 350 and satisfactory model fit at station 360 for both the calibration and validation period. Percent bias and root mean square error indicated a similar performance level at the three stations. The timing of the peaks mostly coincided with the observed peak timing. Some discrepancies were noted in the simulated and observed peak values possibly due to the availability of coarse daily cumulative rainfall data that fail to show the intensity distribution throughout the day and thus cannot replicate the runoff and infiltration process as accurately as desirable. Even with these considerations, the HEC-HMS model performed at a reasonably acceptable level and was able to replicate the rainfall-runoff process of West Rapti basin.

\section{Acknowledgments}

The authors are highly obliged to I.O.E Pulchowk Campus, Khwopa College of
Engineering and S4W-Nepal for rendering a friendly environment for the research work. Also, we are thankful to the reviewers for providing useful comments which improved the paper significantly.

\section{References}

Adhakari, B. R. (2013). Flooding and inundation in Nepal Terai: issues and concerns. Hydro Nepal: Journal of Water, Energy and Environment, 12, 59-65.

Feldman, A. D. (2000). Hydrologic modeling system HEC-HMS: technical reference manual: US Army Corps of Engineers, Hydrologic Engineering Center.

Gebre, S. L. (2015). Application of the HECHMS Model for Runoff Simulation of Upper Blue Nile River Basin. Journal of Waste Water Treatment \& Analysis, 06(02). doi:10.4172/2157-7587.1000199

Halwatura, D., \& Najim, M. M. M. (2013). Application of the HEC-HMS model for runoff simulation in a tropical catchment. Environmental Modelling \& Software, 46, 155-162. doi:10.1016/j.envsoft.2013.03.006

Kafle, M. J. o. (2019). Rainfall-Runoff Modelling of Koshi River Basin Using HEC-HMS. J Hydrogeol Hydrol Eng 8: 1. $9,2$.

Moriasi, D. N., Arnold, J. G., Van Liew, M. W., Bingner, R. L., Harmel, R. D., \& Veith, T. L. (2007). Model evaluation guidelines for systematic quantification of accuracy in watershed simulations. Transactions of the ASABE, 50(3), 885-900.

Paudel, R. C., Basnet, K., \& Sherchan, B. (2019). Application of HEC-HMS Model for Runoff Simulation: A Case Study of Marshyangdi River Basin in Nepal. Paper presented at the Proceedings of IOE Graduate Conference. 
Sampath, D., Herath, S., \& Weerakoon, S. (2015). HEC-HMS model for runoff simulation in a tropical catchment with intra-basin diversions-case study of the Deduru Oya river basin, Sri Lanka.

Talchabhadel, R., \& Sharma, R. (2014). Real Time Data Analysis of West Rapti River Basin of Nepal. Journal of Geoscience and Environment Protection, 02(05), 1-7. doi:10.4236/gep.2014.25001

Wang, M., Zhang, L., \& Baddoo, T. D. (2016). Hydrological Modeling in A Semi-Arid Region Using HEC-HMS. Journal of Water Resource and Hydraulic Engineering, 5(3), 105-115. doi:10.5963/jwrhe0503004 